\title{
O PROJETO TEATRO A BORDO E A DESCENTRALIZAÇÃO DA CULTURA
}

Patricia Limeres Pires

\begin{abstract}
Jornalista graduada pela Universidade Católica de Santos, especializada em Gestão de Eventos Culturais. Trabalha na área de marketing e gestão cultural. Pesquisa realizada sob orientação do Prof. Dr. Juarez Tadeu de Paula Xavier.
\end{abstract}

\section{Resumo}

Este artigo visa a reflexão, a partir das fontes bibliográficas, a respeito da democratização e descentralização cultural necessárias para a formação de um público crítico consumidor de cultura. Para isso, propõe-se a análise do ciclo da cadeia produtiva da cultura, sob o recorte de produção, distribuição e consumo, a fim de identificar os possíveis impactos que comprometam a efetivação desse ciclo. Tal análise é desenvolvida a partir do estudo e observação participativa do projeto "Teatro a Bordo", como alternativa criativa e viável para suprir a carência de infraestrutura para a atividade artística na maioria dos municípios brasileiros.

Palavras-chave: Democratização cultural; indústria cultural; cadeia produtiva; descentralização cultural

\section{Abstract}

This article aims a reflection, from bibliographic sources, about the cultural democratization and decentralization, necessary for the construction of a critical and cultural consumer public. For this purpose, it's proposed the analysis of the cycle of cultural productive chain, under the cutting of production, distribution and consumption, in order to identify the possible impacts that endanger the execution of this cycle. This analysis is developed from the study and participative observation of the project "Teatro a Bordo", while a creative and feasible alternative to furnish the lack of infrastructure for the artistic activity in most of the Brazilian cities.

Keywords: Cultural democratization; cultural industry; commodity chain; cultural decentralization

\section{Resumen}

Este artículo busca una reflexión, a partir de las fuentes bibliográficas, a respecto de la democratización y descentralización cultural necesarias para la formación de un público crítico consumidor de cultura. Para eso, se propone la análisis del ciclo de la cadena productiva de la cultura, bajo el recorte de producción, distribución y consumo, a fin de identificar los posibles impactos que comprometan la conclusión de ese ciclo. Tal análisis es desarrollada a partir del estudio y observación participativa del proyecto "Teatro a Bordo", mientras alternativa creativa y viable para proveer la carencia de infraestructura para la actividad artística en la mayoría de los municipios brasileños.

Palabras clave: Democratización cultural; industria cultural; cadena productiva; descentralización cultural 


\section{Introdução}

O objeto deste artigo é a reflexão a cerca da democratização e descentralização cultural necessárias para a formação de um público crítico consumidor.

Em paralelo, o artigo propõe a análise das relações existentes entre produção, distribuição e consumo de bens culturais - ciclo que compõe a cadeia produtiva da cultura - , tendo em vista a importância de se identificar os possíveis impactos que comprometam a efetivação desse ciclo. Tal análise é desenvolvida a partir do estudo do projeto “Teatro a Bordo - Um Teatro Móvel Num Contêiner”, realizado pela Cia. Abaréteatro, de Itanhaém/SP, como alternativa criativa e viável para suprir, do ponto de vista de mobilidade, a carência de infraestrutura para a atividade artística na maioria dos municípios brasileiros, assim como a própria ausência de programação cultural permanente nessas regiões, cumprindo assim, o fluxo completo da cadeia produtiva, desde a produção até o acesso democrático, que culmina na formação do público.

A reboque do recorte escolhido para a pesquisa detectou-se a necessidade de ir além e observar o projeto objeto de estudo - Teatro a Bordo - inserido no cenário brasileiro de financiamento da cultura, que está ligado à produção. Assim, a pesquisa também perpassa pelo conceito e organização da Indústria Cultural. Para tanto, o artigo apresenta, em parte, a teoria e pensamento crítico do filósofo Theodor Adorno à Indústria Cultural, assim como trabalha o desdobramento do conceito de Indústria Cultural na sociedade moderna sob o olhar de Cremilda Medina, utilizando a metodologia dialética, além da composição de elementos colhidos na observação participante durante o trabalho de campo.

\section{Um palco móvel a serviço da formação}

O projeto Teatro a Bordo - Um Teatro Móvel Num Contêiner foi desenvolvido, em 2007, pela produtora Talita Berthi e utilizado pela Cia. Abaréteatro com lançamento para o público em 2008. No percurso entre a concepção inicial e a realização do projeto ocorreram ajustes de ordem prática, técnica e até conceitual, mas a essência do projeto foi mantida pelo grupo: promover a democratização e a descentralização da cultura.

Teatro a Bordo é um contêiner de 20 pés (6,096 metros), adaptado para um teatro móvel equipado com os recursos técnicos necessários como iluminação, sonorização, tenda e camarins adaptados. 


\section{O PROJETO TEATRO A BORDO E A DESCENTRALIZAÇÃO DA CULTURA}

O objetivo é levar programações culturais diversas e gratuitas, desde teatro até exibição de cinema e oficinas, para regiões e locais onde não haja infraestrutura para a atividade artística e/ou que não promovam relevante acesso do público aos espetáculos com fins culturais e não comerciais, a fim de formar novas plateias e fomentar as já existentes.

"Abrir portas que nunca existiram". Foi com este intento que a Cia. Abaréteatro foi criada, em 1995, na cidade de Itanhaém - Litoral de São Paulo, por Orlando Moreno. A origem do nome da Cia. vem do título do primeiro espetáculo adulto do grupo "O Abaré”, que na língua Tupi significa "O Grande Missionário". Foi pautada nesse desafio que a Cia. desenvolveu seu trabalho artístico, numa cidade pequena e desprovida de espaços convencionais de teatro, realizando espetáculos teatrais de formação de plateia, utilizando a rica cultura popular existente na região como matéria-prima de pesquisa.

Foi a partir dessa busca e necessidade de pensar e de criar espaços alternativos para o "fazer" artístico, além da intenção de promover um circuito cultural, que contasse com uma estrutura ágil e que oferecesse qualidade técnica para o exercício de atividades cênicas, que nasceu o projeto Teatro a Bordo. O conteúdo e as temáticas dos espetáculos da Cia. que compõem a programação do projeto também seguem essa linha de pesquisa de linguagem ligada à cultura popular brasileira, assim como à cultura caiçara.

Mas, por que um contêiner? A resposta dada pelos produtores do projeto, Orlando Moreno (diretor da Cia., coordenador do projeto e ator) e Talita Berthi (atriz da Cia., idealizadora e produtora do projeto), compreende dois aspectos: o simbólico e o técnico. A ideia simbólica refere-se à forte ligação com o mar e com o Porto de Santos, já que a Cia. é do Litoral Paulista. Além disso, Talita explica que é um objeto de troca entre os povos e países. "Ele leva e traz produtos, então, pensamos: por que não trocar culturas também?" (entrevista concedida à autora em 18/07/2009). Em termos técnicos, a opção pelo contêiner é de ordem prática, de agilidade e fácil adaptação. De acordo com a visão compartilhada de Orlando e Talita, "basta engatar um caminhão e levar para qualquer espaço”.

O trabalho de campo permitiu a constatação desse diagnóstico relatado pela direção e produção do projeto, por meio da realização de um mapeamento simplificado dos equipamentos culturais existentes na Baixada Santista. Entre os nove municípios que compõem a região metropolitana, cinco possuem teatro. No total, são 11 casas de espetáculos, sendo seis delas localizadas em Santos. Entre todas, pode-se dizer que três oferecem programação cultural diversificada permanente. 
Esses números não retratam um cenário isolado. Os dados referentes aos demais municípios do País são ainda mais desanimadores. Como menciona Ana Carla Fonseca Reis (2006, p. 142-144), "conforme dados da Pesquisa de Informações Básicas Municipais 1999, do IBGE, a falta de acesso da população brasileira aos equipamentos culturais mínimos é alarmante. Em 84,5\% dos municípios brasileiros não há sequer um teatro".

Neste momento da análise, torna-se importante um destaque: o fator "falta de infraestrutura" provoca um impacto significativo em relação à cadeia produtiva da cultura, no sentido de dificultar ou até impossibilitar uma distribuição efetiva das produções que compromete o consumo, mas não é o único fator impactante nesse processo. Ana Carla Fonseca Reis aponta as principais razões para a não efetivação do ciclo produtivo da cultura,

"A falta de participação nas manifestações e nos equipamentos culturais pode ocorrer por uma
indisponibilidade (podem não existir na comunidade) ou dificuldade de acesso físico a elas; (...) a
falta de tempo ou a inadequação de horários se somam aos fatores que dificultam a participação
de determinados segmentos da população; (...) outro fator que contribui para a existência de não
público é a falta de recursos de grande parte da população para participar de eventos pagos".
(REIS, 2006: p.143-147).

Teatro a Bordo em três recortes:

\section{As engrenagens e complexidades da Produção}

No âmbito produção, existem dois momentos distintos que precisam ser avaliados: o primeiro, mais voltado à produção no sentido de criação e elaboração; e o segundo, relacionado ao desenvolvimento, à realização.

Como o projeto Teatro a Bordo é financiado pela iniciativa privada, via Leis de Incentivo à Cultura, nas instâncias Estadual e Federal, e o artigo também se propõe a levantar possíveis interferências da indústria cultural, no que tange ao financiamento e ao ciclo da cadeia produtiva da cultura com financiamento, cabe uma reflexão a cerca desses recortes.

A partir dessa perspectiva de interferência por parte da indústria cultural, o questionamento que vem à tona, no que diz respeito à produção ainda no campo da criação é: a indústria cultural interfere e/ou condiciona a produção cultural?

Antes de responder, é preciso procurar compreender a forma de organização da Indústria Cultural no Brasil. Indústria Cultural é o termo utilizado para nomear empresas e instituições que trabalham com a produção de projetos, canais, jornais, rádios, revistas e meios de entretenimento baseados na cultura, visando o lucro. Sua 


\section{O PROJETO TEATRO A BORDO E A DESCENTRALIZAÇÃO DA CULTURA}

origem se deu como resultado da sociedade capitalista, que transformou a cultura em produto comercial. Já o conceito de Indústria Cultural, desenvolvido na década 1930, pelos principais pensadores da Escola de Frankfurt, Theodor Adorno e Max Horkheimer, para substituir o termo 'cultura de massas', é mais amplo e complexo. Está ligado ao desenvolvimento industrial e tecnológico da sociedade entre o século XX e XXI. De acordo com Adorno e Horkheimer (2002, p. 07), esse conceito parte de uma perspectiva de que "a cultura contemporânea a tudo confere um ar de semelhança.", implicando na padronização da cultura.

Outra característica que vale destacar é que a produção cultural não se autosustenta. Ela é gerida e mantida pelo Estado ou pelo Capital. Essa é lógica única da indústria cultural, a sua natureza é de ordem econômica. O que a caracteriza, segundo Adorno (2008, p. 192) é “(...) a comercialização das mercadorias culturais produzidas pela indústria, visando deliberadamente o lucro, e não a criação cultural e a formação dos indivíduos, em uma perspectiva mais ampla, de pessoas humanas".

Diante disso, cabe levantar mais um questionamento: qual é a autonomia que a indústria cultural confere à produção? Wolfgang Leo Maar, em A Indústria Cultural Hoje (2008, p. 07), tece uma resposta objetiva "A indústria cultural é o avesso da autonomia".

Assim, levando-se em conta os quadros teóricos apresentados, que culminam na afirmação de que o sistema da indústria cultural tem por objetivo e meta principais a padronização da cultura em série para atingir as massas a fim de aliená-las, sugere-se que a organização da indústria cultural tem sua parcela de interferência na produção cultural, uma vez que a condiciona com vistas ao financiamento, seja público ou privado. Segundo Adorno (2002, p.15) "O mundo inteiro é forçado a passar pelo crivo da indústria cultural. A velha experiência do espectador cinematográfico, para quem a rua lá fora parece continuação do espetáculo que acabou de ver (...) tornou-se o critério da produção". A pesquisa aponta para a necessidade de um aprofundamento nos estudos no que tange ao nível de interferência que a indústria cultural exerce sobre a produção.

No caso de estudo em tela, a interferência da indústria cultural na sua produção é pontual, até pela essência, natureza e objetivo do projeto. No entanto, vale ressaltar que o Teatro a Bordo, em alguns aspectos, se enquadra no conceito de indústria cultural, pois é financiado pela iniciativa privada. $O$ projeto não vende o seu produto cultural, no sentido comercial, mas vende a imagem institucional das empresas patrocinadoras.

Feitas as reflexões a cerca da produção enquanto criação, agora, a pesquisa avança para o segundo momento da produção: realização e desenvolvimento. A ob- 
servação participante possibilitou conhecer toda a engrenagem de funcionamento do projeto entre montagem, realização e desmontagem.

O contêiner do Teatro a Bordo chega ao município que receberá a sua programação e instala-se em locais públicos, como praças, praias e parques. $\mathrm{O}$ caminhão que o transporta se desprende do contêiner, deixando-o sobre rodas, só e em posição de destaque. Seu porte, a princípio, parece tímido. Porém, a partir daí, começa o processo de transformação de um contêiner em palco. Uma das portas laterais do contêiner se abre e todos os equipamentos e materiais técnicos e de cenografia são retirados de dentro, para que toda uma infraestrutura seja montada, com vistas à realização das apresentações com qualidade técnica.

Essa produção envolve 12 profissionais diretos. Para cada dia de apresentação são dedicadas cerca de cinco horas para a montagem e desmontagem de toda a infraestrutura. No período selecionado para o estudo (junho de 2008 a agosto de 2009), a pesquisa registrou que o projeto produziu 630 horas de atividades culturais, gerando uma carga de 910 horas de trabalho, em 91 dias de apresentações.

Os números são relevantes. No entanto, a produção do projeto envolve um número maior de pessoas e profissionais. No total, o projeto tem o envolvimento de cerca de 580 pessoas, entre profissionais do projeto, grupos e artistas contratados para a programação, além dos convidados locais das regiões por onde o projeto passou.

Outro elemento observado durante o trabalho de campo é o envolvimento, a preocupação e o cuidado permanente por parte da equipe com relação à qualidade do desenvolvimento do projeto, demonstrando sempre respeito ao público consumidor.

Um exemplo prático dessa preocupação está relacionado aos ajustes e aprimoramentos pelos quais o Teatro a Bordo passou desde a sua concepção. No início, o projeto não previa bancos ou cadeiras para o público assistir à programação, pois o grupo tinha em mente a questão de ser um projeto realizado na rua - um local de passagem -, mas logo nas primeiras apresentações, a produtora executiva do projeto, Talita Berthi, identificou que os assentos eram essenciais para o conforto do público. Talita relata como se deu a mudança de planos, "Percebemos que não dava. Teatro não dá para assistir em pé. Adquirimos os bancos no hipermercado que ficava próximo ao local das apresentações e eles passaram a fazer parte da estrutura do projeto".

Outra melhoria aplicada foi a confecção de uma lona para proteger o público do sol ou da chuva, já que o projeto é realizado a céu aberto e fica exposto às condições climáticas. De acordo com a produtora Talita, a lona não foi projetada antes para 


\section{O PROJETO TEATRO A BORDO E A DESCENTRALIZAÇÃO}

\section{DA CULTURA}

não caracterizar o projeto como circo, mas "diante da necessidade, a equipe técnica desenvolveu uma estrutura que fugisse ao conceito de arena de circo, comportando cerca de 300 pessoas".

Uma característica, também observada no estudo de campo, no que concerne à produção, é a flexibilidade que o Teatro a Bordo tem no sentido de adaptação. Como o projeto visita municípios pequenos e com espaço físico à disposição limitado, nem sempre é possível instalar as tendas das oficinas e camarim. A produtora do projeto conta que, para resolver essa questão, a equipe desenvolveu um camarim improvisado, para aproveitar o espaço "morto" existente abaixo do palco do projeto. "Quando a porta lateral do contêiner é aberta, são colocadas umas espécies de pernas para sustentar essa porta e transformar o contêiner em palco. Essas pernas, que têm cerca de um metro e meio de altura, ficam escondidas por um tecido preto e esse espaço ficava subutilizado".

A pesquisa constatou que são inúmeros os desafios de uma produção como o Teatro a Bordo. Segundo Talita, o projeto, em termos de produção, desafia tudo. "Ele já começa desafiando, mas depender do tempo, por ser um projeto que é feito na rua, é o maior desafio. A instalação da tenda já ajuda muito, mas em dias de chuva de vento não tem como realizar o projeto, infelizmente".

Contudo, depois de ultrapassados os desafios e concluído o processo de montagem, os personagens dos espetáculos da programação entram em cena e as histórias ganham vida no palco móvel do Teatro a Bordo, por meio dos espetáculos "Faz de Conta Que Tem... História”, "Boi Viramundo", "O Negrinho do Pastoreio", "A Menina e o Sabiá" e "Nau Catarineta".

\section{Mobilidade e responsabilidade na Distribuição}

Nesse campo, existe um ponto que gera polêmica e que merece análise. É o fato de a distribuição, no que se refere às produções oriundas da indústria cultural, estar condicionada aos interesses do financiador: quem paga define onde e como o produto cultural será distribuído, independente do interesse e gosto do público que irá consumir essa produção.

O gerente de Arte e Cultura da Arcelor Mittal Brasil - uma das empresas patrocinadoras do projeto - , Marcelo Santos, confirma que um dos fatores que levou à seleção do Teatro a Bordo foi "a mobilidade que ele tem para atender às cidades onde a empresa possui unidade industrial" (entrevista concedida à autora em 20/07/ 2009).

A circulação do projeto em tela teve início em junho de 2008 e contou com 
o patrocínio da iniciativa privada, das empresas Cosipa e Arcelor Mittal Brasil, por meio da Lei Estadual de Incentivo à Cultura de São Paulo. Para o circuito de 2009, o projeto tem o patrocínio da empresa EDP Bandeirante, também via Lei Estadual de Incentivo à Cultura de São Paulo, para a circulação em São Paulo; e da Investco, via Lei Federal de Incentivo à Cultura, para a programação de Tocantins.

O roteiro de itinerância, entre junho de 2008 e agosto de 2009, realizou um total de 250 apresentações culturais e contemplou 19 municípios: Santos, Guarujá, São Vicente, Peruíbe, Itanhaém, Cubatão, Osasco, Hortolândia, Piracicaba e Bauru, São Sebastião e Caraguatatuba, no litoral norte de São Paulo, e Palmas, Lajeado, Tocantínia, Miracema do Tocantins, Porto Nacional, Brejinho de Nazaré e Ipueiras, em Tocantins.

No projeto de estudo, a distribuição de sua produção cultural se dá sem impactos, pois a produção já foi concebida com o propósito da descentralização e democratização cultural. As únicas dificuldades em termos de distribuição percebidas durante a pesquisa de campo estão relacionadas às limitações de alguns municípios onde a programação foi realizada como ponto de energia insuficiente para a capacidade necessária, por exemplo. Contudo, o projeto cumpriu a sua agenda de circulação se adaptando aos imprevistos e dificuldades encontradas no percurso sem comprometer a essência e qualidade.

\section{A ressignificação dos sentidos a partir do Consumo}

O terceiro recorte da análise refere-se ao consumo dos produtos culturais oferecidos pelo projeto de estudo. É no consumo que se encerra o fluxo da cadeia produtiva da cultura. Sem ele, a produção perde o sentido.

Antes de abordar as questões que permeiam o consumo de produtos culturais é importante retomar um dos pontos mais contundentes do discurso de Theodor Adorno a respeito da Indústria Cultural, que tem conseqüências diretas no consumo. De acordo com Theodor Adorno (1999, p. 32), "a indústria cultural impede a formação de indivíduos autônomos, independentes, capazes de julgar e decidir conscientemente".

O conceito de indústria cultural assume, na sociedade capitalista tardia, segundo Adorno, uma dupla finalidade: ideológica, no sentido de exercer o controle social, e econômico, na medida em que a comercialização capitalista da cultura tornou-se uma poderosa fonte lucrativa para grandes monopólios financeiros. Dessa dupla finalidade, a relacionada à função ideológica atribuída por Adorno ao conceito de Indústria Cultural tornou-se alvo de muitas críticas: 


\title{
O PROJETO TEATRO A BORDO E A DESCENTRALIZAÇÃO
}

\section{DA CULTURA}

"D. Kellner formula objeções à teoria adorniana da indústria cultural. A primeira consiste em afirmar que a indústria cultural só poderia desempenhar a função ideológica atribuída a ela por Adorno mediante a condição da existência de um sistema tão monolítico e manipulativo que (...) colocaria seus receptores numa passividade quase absoluta. A segunda questiona a tese de que a indústria cultural reproduz, (...) de modo uniforme, a ideologia da sociedade existente. Essa tese ignora (...) a capacidade criativa de resignificação própria do público diante da mensagem" (DALBOSCO, 2008: p. 192-193).

Os contrapontos à teoria de origem adorniana não param por aí.

\begin{abstract}
"Por que julgar negativamente e recusar em bloco a cultura de massa? Por que permanecer no saudosismo de uma elaboração elitista das mensagens do conhecimento? Por que atribuir à massa uma sacrossanta ignorância e inconsequência nas suas preferências ou ainda uma passividade de rebanho conduzido? Por que bater no peito pela absoluta objetividade das informações veiculadas? Nada mais que bandeiras ultrapassadas por um conhecimento mais aproximado da comunicação anônima" (MEDINA, 1988: p. 40).
\end{abstract}

A experiência da observação participante, em relação ao recorte do consumo, traz à luz da reflexão elementos que podem contribuir para a construção de um novo olhar e discussão à cerca da produção cultural com vistas à democratização e descentralização da cultura.

Quem apresenta esses elementos é Marielza Oliveira Silva, 36 anos, morena, $1.60 \mathrm{~m}$ de altura, natural de Imperatriz/Maranhão e residente em Palmas/Tocantins há cerca de 11 anos, vendedora ambulante de cachorro quente e mãe de três filhos: Camile, com 4 anos; Karine, com 7; e Jackson, com 12. Marielza é uma, entre os 148 mil espectadores, de todas as idades, que já assistiram à programação do Teatro a Bordo.

Após consumir as apresentações artísticas do projeto, Marielza falou sobre lembranças do seu passado e contou a sua história de vida como quem declama um poema ou compõe uma canção, tamanho era o seu contentamento em compartilhar os impactos causados e as reações desencadeadas por tudo o que os seus olhos viram, seus ouvidos escutaram e seu coração sentiu.

Animada, ela inicia o seu depoimento dizendo "hoje, eu voltei ao passado mesmo. A gente volta à infância vendo um espetáculo como esse" (entrevista concedida em 10/08/2009). E, por ter voltado à fase da infância, ela continua a sua narrativa com base nessas lembranças. Ela relata que, quando criança, vivia no interior, na fazenda da avó, e que não tinha acesso à televisão. "Era aquela história do conto do avô. Aquelas coisas que os mais antigos sempre contam para as crianças. Era a única forma de divertimento que a gente tinha, na verdade."

Nesse momento, ela associa as histórias que ouviu quando criança sobre os 
personagens Lampião, Maria Bonita e Boi-Bumbá com o espetáculo que acaba de assistir e diz, gaguejando, "Ah! Gente, eu nem lembrava mais disso".

Por um instante, no intervalo entre uma frase e outra, ela se dá conta das reações das filhas também. "As minhas filhas estavam maravilhadas. Eu estava me sentindo criança igual a elas. Foi maravilhoso mesmo. Nunca pensei que hoje eu estaria aqui, vivendo esse momento".

Ao assistir ao filme "O Pavão Misterioso", na sessão de curtas-metragens do projeto, mais recordações vieram à tona e Marielza as relata oscilando entre alegria e emoção. "Meu pai gostava muito dos romances escritos em forma de prosa e verso. Ele lia,decorava e recitava um romance chamado 'O Pavão Misterioso' e isso ficou marcado. E, hoje, eu vi aqui a história. E eu já nem lembrava mais os versos”.

Tomada pelo efeito que as imagens, ao vivo, das histórias que ela guardava na memória adormecida causaram, Marielza conseguiu lembrar um trecho do poema que ouvia seu pai recitar e fez questão de declamá-lo:

\author{
"Eu vou contar uma história \\ do Pavão misterioso \\ que levantou o voo da Grécia \\ Com rapaz corajoso \\ Para raptar uma condessa \\ Filha de um conde orgulhoso".
}

Com os olhos marejados, ela sorri e complementa "Se eu achasse esse romance hoje, te juro que me deu uma vontade enorme de comprá-lo para tornar a ler e lembrar aquele tempo que foi muito bom. Meu pai já se foi e é uma lembrança que eu tenho".

Marielza - uma receptora ativa - estabelece uma rápida e inteligente relação entre a tradição oral do passado com a tecnologia e a comunicação de massa do presente, percebe o seu papel e faz uma autocrítica, "uma parte que me toca é em relação a contar histórias para os meus filhos. Porque nessa correria que a gente vive, na era da televisão, acho difícil os pais pararem para contar uma história. A minha filha começou a ver o teatro e falou: mãe eu sei essa história. Aí, eu disse: onde você viu? E ela respondeu: a minha professora me contou na escola. Eu me surpreendi. Ao invés dos pais contarem essas histórias, até como forma de tirar da frente da televisão, do vídeo-game, não, é na escola que eles estão tendo essa cultura e, na verdade, teriam que ter dentro de casa".

Como afirma Ana Carla Fonseca Reis (2006, p. 28), "O consumidor e a sociedade em geral não se mostram passivos nesse processo" e Marielza Oliveira Silva é 


\section{O PROJETO TEATRO A BORDO E A DESCENTRALIZAÇÃO DA CULTURA}

um exemplo vivo dessa afirmativa.

\section{Considerações finais}

A observação participante, atrelada ao quadro teórico de referência, no que tange à produção com vistas à descentralização e democratização cultural, aponta para a confirmação da necessidade de se pensar a produção em dois momentos: o da criação e o da realização. Porque dentro do fluxo da cadeia produtiva da cultura, a produção não pode e não deve ficar isolada das demais etapas do ciclo. Toda produção pressupõem uma distribuição, que resulta no consumo e, por isso, precisa estar vinculada e todos os fatores que possam impactar esse processo devem ser considerados.

Não adianta haver produção se a mesma esbarra na inviabilidade de distribuição e não chega ao público. O processo criativo precisa envolver elementos que ultrapassem a fronteira da criação pela criação, como é o caso do projeto de estudo, que pensa a produção também a partir da criação, com mobilidade e autonomia para circular por regiões sem infraestrutura adequada para atividade artística e que promove o acesso gratuito aos bens culturais produzidos.

No âmbito do consumo, no qual desemboca a produção cultural, é importante destacar o caráter de profundidade do depoimento da consumidora escolhida pela pesquisa. Nele estão embutidas as contradições inerentes ao sistema da Indústria Cultural. Contradições essas que impossibilitam a totalização e a padronização da cultura. Embora a indústria cultural tenha o objetivo e consiga interferir e condicionar a produção a fim de padronizá-la, ela não consegue obter esse resultado no campo da recepção, pois o consumidor não é passivo, mas sim reflexivo. E a indústria cultural, com seus dados, números, públicos definidos e segmentados não tem acesso ao campo da reflexão, pois é um campo fértil e individual composto por valores intangíveis e imensuráveis.

A partir da narrativa da consumidora utilizada como fonte do artigo - que consegue se envolver com o produto cultural e, ao mesmo tempo, se utilizar dele para estabelecer relações entre o passado e o presente, entre a ficção e a realidade, entre a estética e o conteúdo - dá para imaginar um consumidor passivo, vulnerável e alienado, conforme a visão Adorniana? Não em absoluto.

Por essa razão, a indústria cultural exerce uma interferência e predominância relativizada, pois não há como padronizar as formas com que as pessoas recebem a arte como informação, nem tampouco presumir como cada qual resignifica a mensagem que recebe, porque isso depende do histórico, do percurso e do repertório de 
vida de cada ser humano receptor, que é único.

Dessa forma, pode-se dizer que a indústria cultural pode e tem o poder de formar, deformar, conformar e transformar consumidores. E, para que haja a possibilidade concreta de ampliar a promoção de formação e transformação, há que se pensar na criação de outras alternativas, a exemplo do estudo em tela, que sendo de indústria cultural, produz arte com preocupação e respeito ao público; promove e garante a distribuição da sua produção, ainda que condicionada aos interesses do financiador; e possibilita o acesso do público à arte com qualidade.

\section{Referências bibliográficas}

ADORNO, Theodor. "Indústria Cultural e Sociedade" seleção de textos: Jorge Mattos Brito de Almeida; trad. Julia Elisabeth Levy. São Paulo: Paz e Terra, 2002.

. "Os Pensadores - Textos Escolhidos". Trad. Luiz João Baraúna. São Paulo: Nova Cultural, 1999.

DURÃO, Fábio Akcelrud; ZUIN, Antônio; VAZ, Alexandre Fernandez (orgs.). “A Indústria da Cultura Hoje”. São Paulo: Boitempo, 2008.

REIS, Ana Carla Fonseca. "Marketing Cultural e Financiamento da Cultura”. São Paulo: Thomson Learning, 2006.

MEDINA, Cremilda. "Notícia: Um Produto à Venda: Jornalismo na Sociedade Urbana e Industrial”. São Paulo: Summus, 1988. 